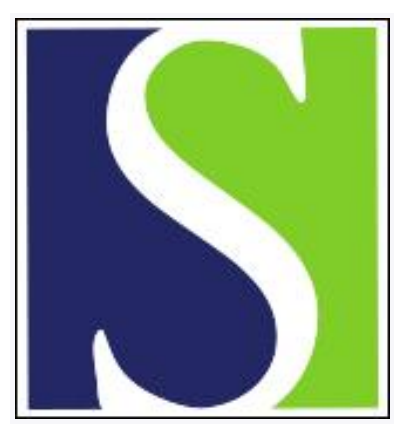

Scand J Work Environ Health 2000;26(3):185-186

https://doi.org/10.5271/sjweh.529

Issue date: Jun 2000

Environment, reproductive health and epidemiology

by Kristensen $P$

This article in PubMed: www.ncbi.nlm.nih.gov/pubmed/10901108

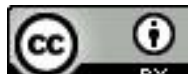

This work is licensed under a Creative Commons Attribution 4.0 International License 


\section{Environment, reproductive health and epidemiology}

Reproduction and developmental health are important societal issues. The pursuit of environmental and occupational causes of adverse outcomes, providing preventive options, has high priority (1). In the 1980s, optimism prevailed, and epidemiology was expected to become a powerful research tool with which to discover preventable causes (2). This expectation has not been fulfilled (3), but we have learned several lessons that may be of help in the future $(4,5)$.

This issue of the Scandinavian Journal of Work, Environment \& Health contains 4 papers in the field of reproductive and developmental epidemiology (6-9). The 4 papers offer an opportunity to rethink and to consider the strength and weaknesses of epidemiology as a tool in this field of research. They illustrate some measures for solving problems; in addition, the contributions are also examples of novel research topics in reproductive and developmental epidemiology.

Male-mediated developmental toxicity has been well documented by animal models, but, so far, examples of the impact of male environmental exposure among humans are scarce and ambiguous (10). Hjollund and his co-workers' study (6) on the effect of stainless steel welding on embryonic loss among spouses is an important leap forwards. I believe that one of the main reasons for this achievement is a specific study hypothesis based on biological knowledge, as well as the pursuit of this hypothesis with a carefully conducted and truly prospective design. Exposure is exactly timed, and the authors use sensitive measures of outcome. If one could wish for more, it might be biomarkers of exposure.

The study of growth, intellectual function, and hearing and visual acuity among young adult sons in Swedish fisher families (9) is in line with the Barker hypothesis (11). In fact, the present study of effects from maternal exposure to persistent organochlorines goes beyond most studies inspired by Barker, which have been investigating associations between antecedents at birth and disease in later life (12). One problem in interpreting the results of Rylander and his co-workers' study is the lack of covariate information, in particular postnatal determinants among the sons. The authors are correct in underlining the need for comparable groups to interpret associations correctly in that it is plausible to assume that postnatal experience has a high impact on study outcomes in early adulthood. A further challenge would be to disentangle and weight the separate effects of prenatal and postnatal influence (13). One example is the low fraction of fishermen's sons with a high general intelligence. It would be interesting to know whether central nervous functions are favored in sons who have been nourished with the natural constituents of fatty fish in pre- and postnatal life, but that this nurturing is outweighed by low education level and other less fortunate socioeconomic factors. It may also be interesting to have results for the sons' height adjusted for maternal smoking, since the eastcoast mothers were likely to smoke more frequently during pregnancy (8).

Cohort designs are well suited in reproductive and developmental epidemiology (14), so it is not coincidental that all 4 studies $(6-9)$ are cohort in nature. The Swedish fisher family cohorts not only serve for studying time to pregnancy (8) and outcomes in adulthood (9), but are also part of a large study program that includes perinatal outcomes (15). One virtue with this strategy is that it makes possible the study of several interrelated outcomes, in which the combined results can add inferential value and credibility.

The problem of less accurate exposure data is well recognized. Not all researchers are as fortunate as the Finns, who have the opportunity to exploit data bases of workers who have been biologically 
monitored for lead (16) and organic solvents (17). It is nice to know, though, that cohorts open the potential for performing nested case-referent studies with better exposure parameters. In fact, the Swedish research group has used biomarkers of exposure in a nested case-referent birthweight study (15), and it could also have this option in the study of other outcomes.

The investigation of the influence of exposure to persistent organochlorines on fecundability and fertility (8) illustrates some of the covariate intricacy in reproductive studies. The apparent difficulty in sorting out separate effects from an exposure, potentially hazardous, contained within fish, with potential beneficial compounds regarding reproduction, has been solved elegantly by the comparison of east- and westcoast fisher families. The nature of influence from other covariates, such as maternal smoking and growing up in a fishing village, may be difficult to interpret. Analytic strategies should be governed by mechanistic assumptions and biological knowledge, and are often difficult. Causal diagrams as a tool in analysis could prove useful in epidemiologic studies on reproductive and developmental outcomes (18).

\title{
References
}

1. Michal F, Grigor KM, Negro-Vilar A, Skakkebæk NE. Impact of the environment on reproductive health: executive summary. Environ Health Perspect 1993;101 suppl 2:159-67.

2. Lockey JE, Lemasters GK, Keye WR Jr, editors. Reproduction: the new frontier in occupational and environmental health research. New York (NY): Alan R Liss, 1984.

3. Kogevinas M, Sala M. Pesticides and congenital malformations - how many studies will it take to reach a conclusion? [editorial]. Scand J Work Environ Health 1998;24:445-7.

4. Bonde JP. Environmental fertility research at the turn of the century. Scand J Work Environ Health 1999;25 (6, special issue): $529-36$.

5. Kristensen P. Parental exposure, adverse pregnancy and offspring effects - perspectives in developmental epidemiology. Scand J Work Environ Health 1999;25 (6, special issue):541-9.

6. Hjollund NHI, Bonde JPE, Kold Jensen T, Brink Henriksen T, Andersson A-M, Kolstad HA, et al. Male-mediated spontaneous abortion among spouses of stainless steel welders. Scand J Work Environ Health 2000;26(3):187-92.

7. Engel LS, O'Meara ES, Schwartz SM. Maternal occupation in agriculture and risk of limb defects in Washington State, 1980-1993. Scand J Work Environ Health 2000;26(3):193-8.

8. Axmon A, Rylander L, Strömberg U, Hagmar L. Time to pregnancy and infertility among women with a high intake of fish contaminated with persistent organochlorine compounds. Scand J Work Environ Health 2000;26(3):199-206.

9. Rylander L, Hagmar L. Medical and psychometric examinations of conscripts born to mothers with a high intake of fish contaminated with persistent organochlorines. Scand J Work Environ Health 2000;26(3):207-12.

10. Olshan AF, Faustman EM. Male-mediated developmental toxicity. Reprod Toxicol 1993;7:191-202.

11. Barker DPJ, editor. Fetal and infant origins of adult disease. London: BMJ Publishers, 1992

12. Joseph KS, Kramer MS. Review of the evidence on fetal and early childhood antecedents of adult chronic disease. Epidemiol Rev 1996;18:158 - 74.

13. Anonymous. Heart disease: in the beginning [editorial]. Lancet 1992;339:1386-8.

14. Joffe M. Detection of agents causing genetic or reproductive damage [editorial]. Br J Ind Med 1992;49:1-4.

15. Rylander L, Strömberg U, Dyremark E, Östman C, Nilsson-Ehle P, Hagmar L. Polychlorinated biphenyls in blood plasma among Swedish female fish consumers in relation to low birth weight. Am J Epidemiol 1998;147:493-502.

16. Lindbohm M-L, Sallmén M, Anttila A, Taskinen H, Hemminki K. Paternal occupational lead exposure and spontaneous abortion. Scand J Work Environ Health 1991;17:95-103.

17. Lindbohm M-L, Taskinen H, Sallmén M, Hemminki K. Spontaneous abortions among women exposed to organic solvents. Am J Ind Med 1990;17:449-63.

18. Greenland S, Pearl J, Robins JM. Causal diagrams for epidemiologic research. Epidemiology 1999;10:37-48

\author{
Petter Kristensen \\ National Institute of Occupational Health \\ Department of Occupational Medicine \\ PO box 8149 Dep \\ N-0033 Oslo Norway \\ [E-mail: petter.kristensen@stami.no]
}

